\title{
Research work culture as an important part of the research activities of undergraduates of the program "Mathematics in professional education"
}

\author{
M.V. Ovchinnikova ${ }^{1 *}$, E.P. Linnik ${ }^{2}$, and I.N. Zinenko ${ }^{3}$ \\ ${ }^{1}$ V.I. Vernadsky Crimean Federal University, Simferopol, Russia \\ ${ }^{2}$ V.I. Vernadsky Crimean Federal University, Simferopol, Russia \\ ${ }^{3}$ V.I. Vernadsky Crimean Federal University, Simferopol, Russia
}

\begin{abstract}
Research activity of a modern graduate of the pedagogical magistracy is a prerequisite for his or her professional and pedagogical activity. Development and implementation of their own pedagogical approaches as well as their own curricula can only be performed by a creative teacher of Mathematics. The one who has a high level of a research work culture. In the process of the research, made on the basis of the integration of culturological, activity-oriented, axiological and personal approaches, the concept of "research work culture" of a Mathematics teacher was updated. In the structure of this concept, four components were identified: cognitive, technological, axiological, and subjective. The results of experimental work on the formation of the research work culture of undergraduates in the direction of training "Pedagogical education" of the program "Mathematics in professional education", showing the effectiveness of the chosen methodology.
\end{abstract}

\section{A problem statement}

The development of education and science is becoming a single synergistic process in which pedagogical universities are given one of the leading roles. Federal educational standards of higher pedagogical education within each and every change continue to emphasize the importance of the research and research work in pedagogical activity.

The research activity of a Mathematics teacher supports the development and use of one's own pedagogical approaches and curricula and becomes an essential condition for the work of a creative Mathematics teacher (The Concept of Development of Mathematical Education in the Russian Federation, Moscow (2013)), therefore, the professional and pedagogical training of a Mathematics teacher in a Master's Degree program is aimed at the scientific and pedagogical research [1].

\footnotetext{
*Corresponding author: prof-ped.gpa@mail.ru
} 


\subsection{The objective of the work}

In modern studies of the development of higher pedagogical education in the Russian Federation, many researchers pay attention to the personnel training in a Master's Degree program.

In the research [2] gives the analyses of transformations of Magistracy in Russia in three vectors: changes in educational paths, staffing and design of Master's Degree programs. The author says, that the system of Master's Degree education in Russia in now being transformed. It is influenced by the global trends in higher education and stakeholders' needs.

The study [3] analyzes the features of the pedagogical Magistracy as a separate stage of higher education, which distinguishes it from the Bachelor's degree. The results of the questionnaire survey of graduate students, their reflexive texts, allowing to record the "portrait" of a student of a magistracy in Pedagogics: motivation of applying to the Magistracy, their expectations, as well as difficulties and effects of the first months of training are provided by the author. The author proposes to change the models of organizing joint activities and the type of communication between the teacher and the Master's Degree students in order to change the type of educational activity of the Master's Degree student and the professional competencies of the teacher when entering the Master's Degree program.

Some aspects of the formation of professionalism of teachers are devoted to research [4 -9]. Many studies are devoted to the use of digital technologies in the professional training of teachers, as well as various forms of application in the educational process of teaching at various educational levels [10-13].

The results of research on the professional training of a future Mathematics teacher and the peculiarities of studying mathematical disciplines in higher education are given in the works [14-18].

\section{Results of the research}

Master's degree programme and the their training process, e.i. future teachers of Mathematics in the modern system of higher pedagogical education is aimed at creating conditions for the creative development of a gifted person and the building of his or her professional and social qualities in one of the functional areas of activity: research (creative), scientific and pedagogical, as well as administrative ones [19]. The graduate of the Master's degree program must have deep and fundamental knowledge not only in Mathematics and Pedagogy, but also innovative skills, research (creative) skills, or scientific and pedagogical or administrative activities, acquire some experience in using the knowledge gained and be able to produce (create) elements of new knowledge to solve problems in teaching Mathematics in educational institutions of different levels. Therefore, higher educational institutions are obliged to create conditions for the full implementation of the individual plan for persons enrolled in the Master's degree program.

Modern undergraduates have the opportunity to:

- publish the results of their scientific (scientific and methodological) research;

- to publish their Master's paper in the form of a scientific monograph, scientificmethodological and educational manual;

- to use classrooms, scientific funds of the library, scientific equipment;

- use information networks;

- participate in scientific and methodological conferences at various levels, scientific and scientific-methodological contests and competitions; 
- use various Internet platforms, attend optional courses on problematic issues with the participation of prominent scientists-methodologists in Mathematics within the framework of networking, cooperation between universities.

The authors [20] analyze the state of the building of the research work competence of students of pedagogical Bachelor's and Master's degrees programmes. They developed and implemented the author's methodology for working with key scientific concepts that constitute the theoretical basis of any scientific pedagogical research. The ability to form scientific concepts is one of the components of the research competence of a modern teacher, who, in accordance with his labor functions, is obliged to direct the research and project activities of students in all educational systems. According to the authors, research work competence consists of two groups of research skills (working with literary sources and working with the research text).

The direction of the research work within the training process of Master's Degree programme in teaching Mathematics includes in-depth fundamental mathematical and methodological-mathematical professional training and the formation of practical personal skills for subsequent research work in educational institutions or continuing education in graduate school. In the process of training, the undergraduate must learn to solve the following problems:

- conducting scientific and pedagogical research in separate sections of the topic, including the implementation of complex experiments and observations;

- participation in the creating and developing plans for research activities and methodological programs of research and development, statistical processing and analysis of the results of experiments and observations;

- development of quality assessment methods, substantiation of technological levels and efficiency of production processes.

One of the most important components of research activities is the research culture of a Master's Degree programme student.

Within the research work culture in the aspect of its collective bearer, we understand the historically conditioned level of development of the scientific community, the creative forces and abilities of its members, expressed in the corresponding types and forms of organization of their research activities and relationships that take place in the field of scientific communications, and also in the material and spiritual values created by them [21]. In this context, research work culture is a process and a product of the moral production of society as a system for the creation, accumulation, storage, dissemination and development of special moral values, norms, knowledge, ideas, meanings and symbols that play an important role in the field of science. It forms the moral world of the scientific community and its members, provides them with a differentiated system of knowledge, methods of action and value orientations necessary for the implementation of all types of scientific knowledge, scientific work and scientific communications that exist in society. In the field of research work culture, those ideas, norms, meanings and goals are produced that guide the members of the scientific community when regulating the entire wealth of accumulated forms of research activities. Research work culture, as a certain system of values and standards that direct human activity, which materializes these values in its results, appears as the leading path for the development of his creative abilities as a subject of knowledge, communication and labor.

The research culture of a Master's degree programme student - a future teacher of Mathematics - is a characteristic of the qualitative state of his personality as a subject of knowledge, communication and labor, reflects the regulatory requirements for the implementation of research activities and forms of his or her behavior in the field of communication in the scientific community, as well as the degree of his or her development in the specified social role. Research work culture is a way of organizing the life of a future 
Master's Degree holder, which ensures his or her comprehensive humanistic self-realization as a subject of cognition, communication, cooperation and co-creation, and thereby contributes to the progressive development of science at the level of Master's Degree studies as a special part of the sphere of social consciousness and social practice.

The experiment was based on the Humanities and Education Science Academy (Branch) of V.I. Vernadsky Crimean Federal University. The experimental sample consisted of 38 students of 2 academic groups of the first and second years of the direction of training "Pedagogical education" Master's Degree programme "Mathematics in professional education".

The formation of such a sample was determined by the narrow specialization of the research and by exactly the same number of groups of undergraduates in this specialty. At the same time, we took into account the fact that the presence of control groups is not necessary, since it is not always possible to ensure the equality of the conditions at the begging of the experiment.

The experimental part of the study of the process of forming the research activities of undergraduates in the field of study 44.04.01 "Pedagogical education", the Master's degree programme "Mathematics in professional education" was implemented with undergraduates of the first and second years of study. For the experiment conducted by second-year undergraduates as an experimental group, undergraduates of the first year of study of a similar direction of training (group G1) were selected.

At the beginning of the 2019/2020 academic year, undergraduates of the second year of study received the task to conduct a research related to the integration of their own educational and research activities. The task was formulated in accordance with the initiative scientific research on the topic "Integration of educational and research activities of future Mathematics teachers in the context of their personality-oriented professional training" (R\&D registration number AAAA-A18-118041190060-7 from 11.04.2018)

The general decision of the group was: to investigate the state of formation of the research culture of undergraduates of the first year of study, to carry out measures for its correction and formation.

Simultaneously with the work, undergraduates of the second year of studies were also participants in the experiment on the formation of their own mathematical culture (group $\mathrm{G} 2)$.

The experimenters developed a research program, which was approved at the meeting of the Department of Mathematics, Theory and Methods of Teaching Mathematics.

In the theoretical part, the basic concepts of the research were determined, the component composition of the phenomenon of the research work culture of future Mathematics teachers was developed, the levels of its formation were determined.

In the practical part, a four-component model of the research work culture of a mathematics teacher was implemented.

Let's have a look at the obtained results.

In the definitions of the phenomenon of "culture", famous scientists indicate the presence of a certain amount of knowledge, skills, values and ideals. Based on the integration of culturological, activity-oriented, axiological and personal approaches in their unity to understanding the essence of the phenomenon of "research work culture", four main components were identified in its structure:

1) cognitive (subject-content function, determines the system of actions of a Master's degree programme student according to the competent definition of the conceptual and empirical research apparatus; implementation of the forms of logical thinking and search strategies, adequate perception, processing and interpretation of scientific facts corresponding to the subject of research);

2) technological (procedural and operational function, determines the system of actions 
of the undergraduate for the adequate use at each stage of research of the technological tools of scientific creativity (theoretical, empirical and statistical research methods); the implementation of constructive means and techniques of scientific communication and interpersonal communication);

3) axiological, (value-orientational function, determines the system of actions of the undergraduate in its stable focus on certain methodological attitudes and principles of scientific knowledge; acceptance and observance of humanistic values, ideals, norms, rules and ethical canons of behaviour in the field of scientific communication, generally accepted by the scientific community, cooperation and co-creation);

4) subjective (reflexive-creative function, determines the system of actions of the undergraduate in a conscious and responsible attitude towards oneself as a "man of science", constantly develops and grows in the perspective of the roles of a researcher, scientist; continuous self-understanding and self-knowledge, self-education of necessary and professionally important qualities, their creative self-realization in the field of scientific knowledge, communication, cooperation and co-creation).

The level of research culture testifies to the degree of Master's degree of mastery of the component-functional structure of research activity, the implementation of its essential forces in the process of mastering values and the results of scientific knowledge, as well as in the method and degree of development of its general and special abilities, cognitive needs, interests, ideals.

The measurement of the levels of formation of the research work culture of undergraduates was carried out in accordance with the selected levels.

The high level of the research work culture of the undergraduate provides a thorough mastery of the conceptual (knowledge of the foundations of science philosophy, theory and methodology of scientific research) and empirical (the presence of a stable and flexible algorithm of theoretical and practical actions for the research, perception, processing and evaluation of scientific knowledge, the ability is most expedient and effectively use various principles, means and methods at the main stages of research), the conceptual apparatus of methodological and mathematical science; the presence of a pronounced moral and ethical research position (humanistic personal meanings and key values in the field of research activities; ideals of the personality and activities of the subject of cognition, communication and cooperation as strategic proper images) and the creative orientation of the individual (the ability to most effectively realize his personal potential as subject of knowledge).

A sufficient level of the research work culture of the undergraduate provides: a sufficiently thorough knowledge of the conceptual (knowledge of the foundations of the science philosophy, theory and methodology of scientific research) and empirical (the presence of a stable and flexible algorithm of theoretical and practical actions for the search, perception, processing and evaluation of scientific knowledge, the ability to it is advisable and effective to use various principles, means and methods at the main stages of research), the conceptual apparatus of methodological and mathematical science; the presence of a noticeably pronounced moral and ethical research position (humanistic personal meanings and key values in the field of research activities; ideals of the personality and activities of the subject of cognition, communication and cooperation as strategic proper images) and the creative orientation of the individual (the ability to quite effectively realize his or her personal potential as subject of knowledge).

The average level of the research culture of the undergraduate provides: satisfactory mastery of the conceptual (awareness of the foundations of the science philosophy, theory and methodology of scientific research) and empirical (the presence of a fairly stable, but not always flexible algorithm of theoretical and practical actions for the search, perception, processing and assessment of scientific knowledge, the ability to expediently and effectively use various principles, means and methods at the main stages of research), the 
conceptual apparatus of methodological and mathematical science; the presence of personal meanings and key values in the field of research activities, ideals of the personality and the activity of the subject of cognition, communication and cooperation as strategic images of the proper and creative orientation of the individual (the ability to quite effectively realize one's personal potential as a subject of cognition).

A satisfactory level of the research culture of the undergraduate provides: satisfactory mastery of the conceptual (insufficient awareness of the foundations of the science philosophy, theory and methodology of scientific research) and empirical (the presence of an insufficiently stable and flexible algorithm of theoretical and practical actions for the search, perception, processing and assessment of scientific knowledge, the ability it is advisable, but not always effective, to use various principles, means and methods at the main stages of research), the conceptual apparatus of methodological and mathematical science; the presence of weakly expressed personal meanings and key values in the field of research activities, the ideals of the personality and the activity of the subject of cognition, communication and cooperation as strategic images of the proper, single manifestations of the creative orientation of the individual (the ability to quite effectively realize his personal potential as a subject of scientific knowledge).

The low level of formation of the research culture of the master provides for: amateurish knowledge of the conceptual (superficial knowledge of the foundations of the science philosophy, theory and methodology of scientific research) and empirical (the presence of an algorithm of theoretical and practical actions for the search, perception, processing and evaluation of scientific knowledge, the ability to use various principles, by means and methods at the main stages of research) by the apparatus of methodological and mathematical science; the presence of a barely expressed moral and ethical research position (personal meanings and key values in the field of research activities; ideals of the personality and activities of the subject of cognition, communication and cooperation as strategic proper images) and isolated manifestations of the creative orientation of the individual (the ability in rare cases to realize his or her personal potential as a subject of knowledge).

In the course of the experimental work, 3 diagnostic sections of the research were carried out: initial, intermediate and final. The data of diagnostic sections carried out during the period of experimental work are shown in Tables 1-3.

Table 1. Results of the initial diagnostic section.

\begin{tabular}{|c|c|c|c|c|c|}
\hline \multirow{2}{*}{ Groups } & \multicolumn{5}{|c|}{ Components of a research culture } \\
\cline { 2 - 6 } & Cognitive & Technological & Axiological & Subject & $\begin{array}{c}\text { Total } \\
\text { Coefficient }\end{array}$ \\
\hline G1 & 0.31 & 0.31 & 0.18 & 0.22 & 0.26 \\
\hline G2 & 0.29 & 0.29 & 0.20 & 0.20 & 0.25 \\
\hline
\end{tabular}

As can be seen from Table 1, the level of formation of each of the components of the research work culture is at a low level. This level was expected and typical for undergraduate graduates, where research activities are formed at lower levels.

The difference between the G1 and G2 groups is also little. This is due to the fact that a purposeful program for the development of research work culture was not implemented in these groups.

The intermediate assessment in Table 2 shows an increase in each of the components, as well as an increase in the overall coefficient of the level of research work culture. This confirms the correctness of the chosen direction. 
Table 2. Results of the intermediate diagnostic section.

\begin{tabular}{|c|c|c|c|c|c|}
\hline \multirow{2}{*}{ Groups } & \multicolumn{5}{|c|}{ Components of a research culture } \\
\cline { 2 - 6 } & Cognitive & Technological & Axiological & Subject & $\begin{array}{l}\text { Total } \\
\text { Coefficient }\end{array}$ \\
\hline G1 & 0.58 & 0.56 & 0.56 & 0.57 & 0.57 \\
\hline G2 & 0.60 & 0.59 & 0.60 & 0.59 & 0.60 \\
\hline
\end{tabular}

Table 3. Results of the final diagnostic section.

\begin{tabular}{|c|c|c|c|c|c|}
\hline \multirow{2}{*}{ Groups } & \multicolumn{5}{|c|}{ Components of a research culture } \\
\cline { 2 - 6 } & Cognitive & Technological & Axiological & Subject & $\begin{array}{l}\text { Total } \\
\text { Coefficient }\end{array}$ \\
\hline G1 & 0.81 & 0.80 & 0.83 & 0.82 & 0.82 \\
\hline G2 & 0.80 & 0.79 & 0.81 & 0.81 & 0.80 \\
\hline
\end{tabular}

The last diagnostic assessment showed an increase in the coefficients for each of the components and the overall coefficient by 0.56 and 0.55 , respectively.

\section{Conclusions}

Thus, the conducted research has shown that the chosen directions are correct. The methodology for the formation of the research work culture of undergraduates of future mathematics teachers proves to be effective. The implementation of the developed model showed an increase in the level of formation of the research work culture of undergraduates. The construction of the concept of the formation of research activities of future teachers of Mathematics creates opportunities for the development and application of theory, methods and technology of its practical implementation in a pedagogical university.

\section{References}

1. N. Gluzman, T. Sibgatullina, A. Galushkin, I. Sharonov, Forming the Basics of Future Mathematics Teachers' Professionalism by Means of Multimedia Technologies, EURASIA Journal of Mathematics, Science and Technology Education, 14(5), 1-13 (2018)

2. Ye.A. Opfer, Transformation of the russian master's school, Higher education in Russia, 30, 36-48 (2021)

3. S. Pozdeeva, Master's Degree Environment As A Space For Personal Professional Development Of Students And Professors, Higher education in Russia 3(210), 144-152 (2018)

4. N.P. Volkova, O.B. Tarnopolsky, I.V. Olyinik, The individual style of speech of teachers from higher education institutions as an indicator of pedagogical professionalism Espacios, 40, 30-32(2019)

5. I. Donina \& E. Vezetiu, Teacher's readiness for marketing activities as a condition of quality education, The European Proceedings of Social \& Behavioural Sciences, 59, 933-940 (2019)

6. M. Evens, J. Elen, C. Larmuseau, \& D. Fien, Promoting the development of teacher professional knowledge: Integrating content and pedagogy in teacher education, Teaching and Teacher Education, 75, 244-258 (2018) 
7. S. Wang, N. Gorbunova, A. Masalimova, J. Bírová, M. Sergeeva, Formation of academic mobility of future foreign language teachers by means of media education technologies, Eurasia Journal of Mathematics, Science and Technology Education, 14(3), 959-976 (2018)

8. S. Pozdeeva, University teacher: methodologist, reseacher, novator?, Higher education in Russia, 3(210), 52-58 (2017)

9. F. Lauermann, \& J. König, Teachers' professional competence and wellbeing: Understanding the links between general pedagogical knowledge, self-efficacy and burnout, Learning and Instruction, 45, 9-19 (2016)

10. O. Pankratova, E. Konopko, R. Nemkov, \& O. Mezentseva, The preparation of a modern Computer Science teacher with the help of resource-saving technologies and Green IT implementation, Integrating Research Agendas and Devising Joint Challenges International Multidisciplinary Symposium ICT Research in Russian Federation and Europe, 222-228 (2018)

11. Z. Smirnova, N. Kamenez, O. Vaganova, L. Kutepova \& E. Vezetiu, The experience of using the webinar in the preparation of engineering specialists, Amazonia Investiga, 8(18), 279-287 (2019)

12. E. Chernysheva, E. Kubryakov, The experience of practice-oriented training model implementation for teacher-training education university students, specialising in physics and mathematics, Perspectives of Science \& Education, 5(35), 65-73 (2018)

13. E. Smirnov, T. Zykova \& S. Tikhomirov, The management of school mathematical education with synergistic effect, Perspectives of Science \& Education, 2(38), 190-202 (2019)

14. G. Zamaletdinova, N. Konopleva, N. Gluzman, N. Gorbunova, Development of electronic educational resources for studying mathematics by adobe flash and systems at elementary schools, The Journal of Social Sciences Research, 1, 171-174 (2018)

15. E. Gusakova \& T. Gusakova, Active methods in teaching mathematics in high school Perspectives of Science \& Education, 1(31), 33-38 (2018)

16. P. Gorev, \& A. Kalimullin, Structure and Maintenance of a Mathematical Creative Lesson as a Mean of Pupils' Meta-Subject Results Achievement, EURASIA Journal of Mathematics, Science and Technology Education, 13(6), 2701-2720 (2017)

17. D. Gorev, \& I. Gurevich-Leibman, Experience of Integrating Various Technological Tools into the Study and Future Teaching of Mathematics to Education Students, International Journal of Mathematical Education in Science and Technology, 46(5) 737-752 (2015)

18. E. Smirnov, S. Tikhomirov \& S. Dvoryatkina, Self-organization technology of student's mathematical activities based on intelligent management, Perspectives of Science \& Education, 3(45), 77-86 (2020)

19. I. Pokornaya, S. Titorenko, \& A. Ovsiannikova, Some issues of improving the training of masters of the field 44.04.01 Pedagogical education under the program "Math education", Perspectives of Science \& Education, 3(39), 184-195 (2019)

20. T.F. Orekhova, T.G. Neretina, E.N. Kondrashova, Formulation of a scientific concept as a component of the research competence of future teachers, Higher education in Russia, 28, 149-157 (2019)

21. A. Zhafyarov, Competence approach: Consistent theory and technology, Science for Education Today, 9(2), 81-95 (2019) 